\title{
On the Effects of Zirconium Upon the Age-Hardening and Grain Size of Cu-Ni-P Alloys*
}

\author{
By Toshio Doi**
}

\begin{abstract}
Effects of zirconium upon the softening, aging, grain size and microstructure of $\mathrm{Cu}-1.1 \% \mathrm{Ni}-0.22 \% \mathrm{P}$ alloys have been investigated.

Age hardenability of copper alloys containing $1.0 \sim 1.2 \%$ nickel, $0.20 \sim 0.24 \%$ phosphor and $0.1 \sim 0.2 \%$ zirconium is large, while the grain growth is suppressed.

Grain refinement of $\mathrm{Cu}-\mathrm{Ni}-\mathrm{P}$ alloys by addition of zirconium is due to the presence of precipitates containing zirconium atoms.

The relation among volume fraction of precipitate $f$, mean curvature of precipitate $R i$ and mean curvature of grain boundary $R$ is given by $R / R i=0.15 / f$.

Precipitation has been found in the alloys containing zirconium up to $0.2 \%$ at temperatures of $300^{\circ}$ and $500^{\circ} \mathrm{C}$, but the crystal structure of the precipitates can not be determined by the X-ray diffraction technique.

(Received August 29, 1964)
\end{abstract}

\section{Introduction}

Since 1925, numerous reports have been published concerning Cu-Ni-P alloys. ${ }^{(1) \sim(5)}$ It was in 1940 that

* Read at the April, 1963, meeting of the Japan Institute of Metals at Tokyo, andpublished originally in Japanese in the Journal of the Japan Institute of Metals 27 (1963), 454.

** Central Research Laboratory, Hitachi, Ltd.

(1) T. G. Bamford : J.I.M., 33 (1925), 167.

(2) E. W. Wise : Trans. AIME, 78 (1928), 515.

(3) P. D. Merica : Trans. AIME, 99(1932), 16.

(4) E.C. Rollason and T. G. Bamford: Metals and Alloys 6 (1935), 345.
Crampton and Burghoff ${ }^{(6)}$ presented comprehensive findings concerning the solubilities of $\mathrm{Ni}$ and $\mathrm{P}$ in $\mathrm{Cu}$, optimum amounts and ratios of $\mathrm{Ni}$ and $\mathrm{P}$, and heat treatment conditions. According to these findings, the variations in solubility within the temperature range of $600^{\circ} \mathrm{C} \sim 850^{\circ} \mathrm{C}$ were extremely large. It is clear that the best mechanical characteristics and electrical conductivity are obtained when an alloy which is $5: 1$ in

(5) D. K, Crampton and H. L. Burghoff :U.S.Patent 2, 155, 405 , $2,155,407.2,155,408(1939)$

(6) D. K. Crampton and H.L. Burghoff : Trans. AlME., 137 (1.940), 354 . 
the Ni-P ratio and 1.25 1.5wt $\%$ in the total of $\mathrm{Ni}$ and $\mathrm{P}$ is quenched from $790^{\circ} \mathrm{C}$ and age-hardened at a temperature of $425^{\circ} \sim 480^{\circ} \mathrm{C}$. Crampton and Burghoff (7) also studied the effects of additional elements. It wes reported that the cutting ability is improved by the addition of $\mathrm{Te}$, and that the addition of $\mathrm{Be}, \mathrm{Zn}, \mathrm{Se}$, $\mathrm{Te}, \mathrm{Sn}$, and $\mathrm{Sn}+\mathrm{Cd}$ improve the tensile strength but cause deterioration of the electrical conductivity. However, when these alloys are heated to high temperatures, there is the defect that the grains become coarse. Therefore, to lessen this defect, it was decided to study the effects of additional zirconium.

\section{Samples and Test Methods}

\section{Samples}

The standard composition of the Cu-Ni-P alloys was $1.1 \mathrm{wt} \%$, Ni $0.22 \mathrm{wt} \% \mathrm{P}$ and the balance $\mathrm{Cu} . \mathrm{Zr}$ amounting up to about 1 wt $\%$ was added. The alloys were made by means of vacuum melting. $40 \mathrm{~mm} \phi$ ingots were obtained by forging and reduced to $10 \mathrm{~mm}$ $\phi$ by means of wire drawing. In the final process, the $10 \mathrm{~mm} \phi$ alloys were heated in hydrogen for two hours at $800^{\circ} \mathrm{C}$, water quenched, and, then subjected to cold drawing down to $1 \mathrm{~mm} \phi$. The chemical composition of the samples is listed in Table 1.

Table 1 Chemical conpositions of samples.

\begin{tabular}{c|c|c|c|c}
\hline No. & $\mathrm{Cu}(\mathrm{wt} \%)$ & $\mathrm{Ni}(\mathrm{wt} \%)$ & $\mathrm{P}(\mathrm{wt} \%)$ & $\mathrm{Zr}(\mathrm{wt} \%)$ \\
\hline $\mathrm{Z}-1$ & 98.60 & 1.14 & 0.22 & 0 \\
$\mathrm{Z}-2$ & 98.56 & 1.13 & 0.21 & 0.06 \\
$\mathrm{Z}-3$ & 98.49 & 1.12 & 0.22 & 0.13 \\
$\mathrm{Z}-4$ & 97.70 & 1.13 & 0.23 & 0.89 \\
\hline
\end{tabular}

\section{Test methods}

Specimens produced by the above-mentioned $99 \%$ cold working, as well as those water quenched after heating for one hour at $800^{\circ} \mathrm{C}$, were heated in hydrogen for one hour at temperatures ranging from $200^{\circ}$ to $1000^{\circ} \mathrm{C}$ (at intervals of $50^{\circ}$ or $100^{\circ}$ ) and then gradually cooled. After this, their tensile strength, elongation, hardness $(\mathrm{Hv})$, grain size, electrical resistivity, optical microscopic structure, and electron microscopic structure were studied. Furthermore, in order to obtain a better understanding of the precipitation, specimens which were water quenched after heating for one hour at $800^{\circ} \mathrm{C}$ were heated at a constant rate of $3.7^{\circ} \mathrm{C} / \mathrm{min}$ and the changes in the electrical resistivity were examined.

\section{Results}

\section{Annealing softening}

The softening caused by annealing is shown in Fig. 1. Assuming the tensile strength in the worked state to be $\sigma_{W}$ and that at the annealed state to be $\sigma_{A}$, and defining the softening temperature $T_{S}$ as the temperature giving a value of $1 / 2\left(\sigma_{W}-\sigma_{A}\right)+\sigma_{A}$, the value of

(7) D. K. Grampton and H. L. Burghoff : U.S. Patent 2, 309, 101-3 (1943), 2, 261, 975 (1941), 2, 375, 285 (1945).
$T_{S}$ will be given as shown in Table 2 . In other words, it is clear that the addition of approximately $0.06 \mathrm{wt} \%$ of zirconium will slightly raise the softening temperature of the Cu-Ni-P alloy, but its addition of more than $0.13 \mathrm{wt} \%$ will lower it. The hardness also changes in

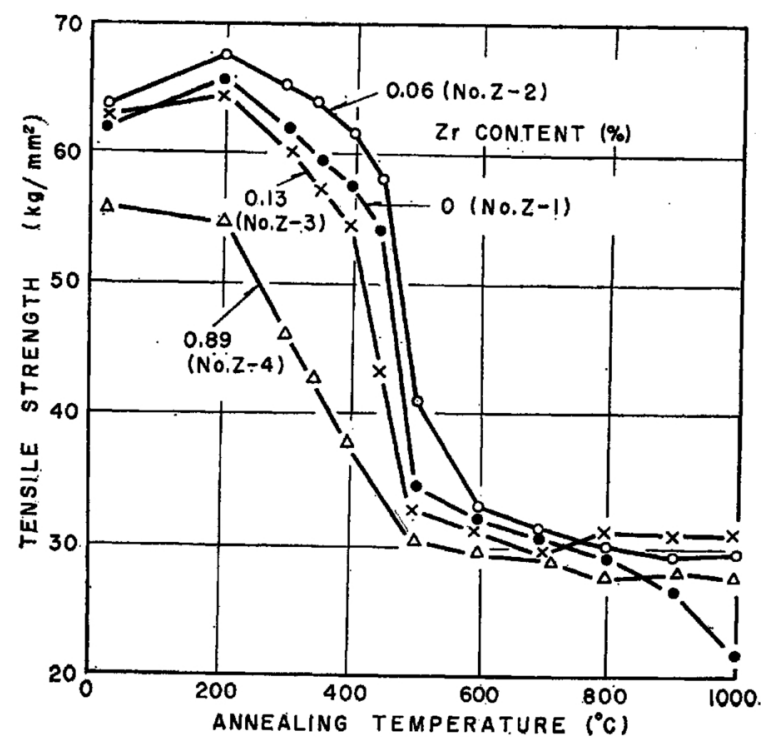

Fig. 1 Effect of the $\mathrm{Zr}$ content on the tensile strength of $\mathrm{Cu}-\mathrm{Ni}-\mathrm{P}$ alloys.

Table 2 Softening temperature of $\mathrm{Cu}-\mathrm{Ni}-\mathrm{P}$ alloys containing $\mathbf{Z r}$.

\begin{tabular}{c|c|c|c|c}
\hline $\mathrm{Zr}$ content $(\%)$ & 0 & 0.06 & 0.13 & 0.89 \\
\hline $\operatorname{Ts}\left({ }^{\circ} \mathrm{C}\right)$ & 470 & 480 & 430 & 350 \\
\hline
\end{tabular}

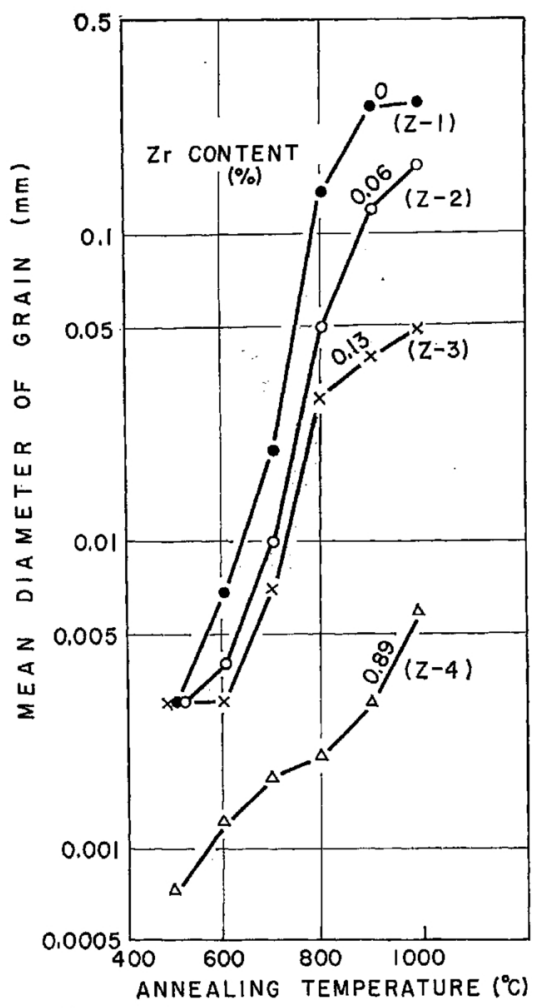

Fig. 2 Effect of $\mathrm{Zr}$ content on grain size of $\mathrm{Cu}-\mathrm{Ni}-\mathrm{P}$ alloys annealed for 1 hour.

a manner similar to the tensile strength : the $\mathrm{Hv}$ is approximately 200 in the worked state, and approxi- 
mately 80 in the annealed state. There was a very little difference in the elongation, which had a-maximum value of about $40 \%$. As for the electrical resistivity, the minimum value for the specimens with $0 \sim 0.13$ wt $\% \mathrm{Zr}$ appeared at about $500^{\circ} \mathrm{C}$, while the minimum value for those with $0.89 \mathrm{wt} \% \mathrm{Zr}$ was found at about $600^{\circ} \mathrm{C}$. With regard to the grain size, the addition of zirconium had an extremely large effect, as shown in Fig. 2. For example, when the specimens containing 0.89 wt $\% \mathrm{Zr}$ were annealed at $1000^{\circ} \mathrm{C}$, the mean diameter of the grains decreased to about $1 / 50$ of that of alloys containing no zirconium.

\section{Age-hardening}

The age-hardening characteristics are shown in Fig. 3. When alloys with $0 \sim 0.13 \mathrm{wt} \% \mathrm{Zr}$ were subjected to aging at $300^{\circ} \sim 500^{\circ} \mathrm{C}$, their tensile strength increased by $10 \sim 15 \mathrm{~kg} / \mathrm{mm}^{2}$. On the other hand, there was

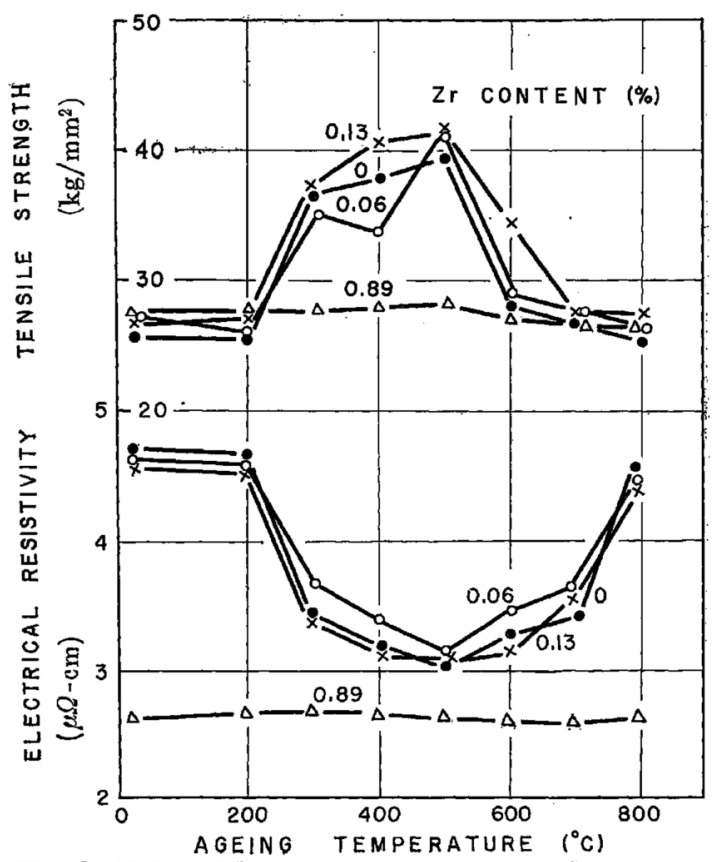

Fig. 3 Effect of $\mathrm{Z}_{\mathrm{r}}$ content on tensile strength and electrical resistivity of $\mathrm{Cu}-\mathrm{Ni}-\mathrm{P}$ alloys. (aged for 1 hour)

virtually no hardening in the specimens with $0.89 \mathrm{wt}$ $\% \mathrm{Zr}$. The elongation was $30 \sim 40 \%$ in the annealed state and $10 \sim 20 \%$ in the hardened state. The hardness, as in the case of annealing softening, showed a tendency similar to that of the tensile strength. As for the electrical resistivity, the minimum value for the specimens with $0 \sim 0.13$ wt $\% \mathrm{Zr}$ was found by aging at $500^{\circ} \mathrm{C}$. Age hardening caused little variations in the electrical resistivity in the specimens with $0.89 \% \mathrm{Zr}$. In the same way as in annealing, there was an increase in the electrical resistivity during aging of the specimens containing $0.06 \mathrm{wt} \% \mathrm{Zr}$, whereas there was a decrease in the specimen containing more than 0.13 wt $\%$. Since the electrical resistivity of the specimens containing no $\mathrm{Zr}$ during the $500^{\circ} \mathrm{G}$ agehardening is $3.02 \mu \Omega-\mathrm{cm}$, this value will be equivalent to $57 \%$ when converted to the electric conductivity.

\section{Electrical resistivity and temperature variations}

When the specimens containing no zirconium were heated at a constant rate there were two depressions in the electrical resistivity versus temperature curves as shown in Fig. 4 (a). These depressions appeared at 280 ${ }^{\circ} \mathrm{C}$ and at $530^{\circ} \mathrm{C}$. During cooling, there was a bend at

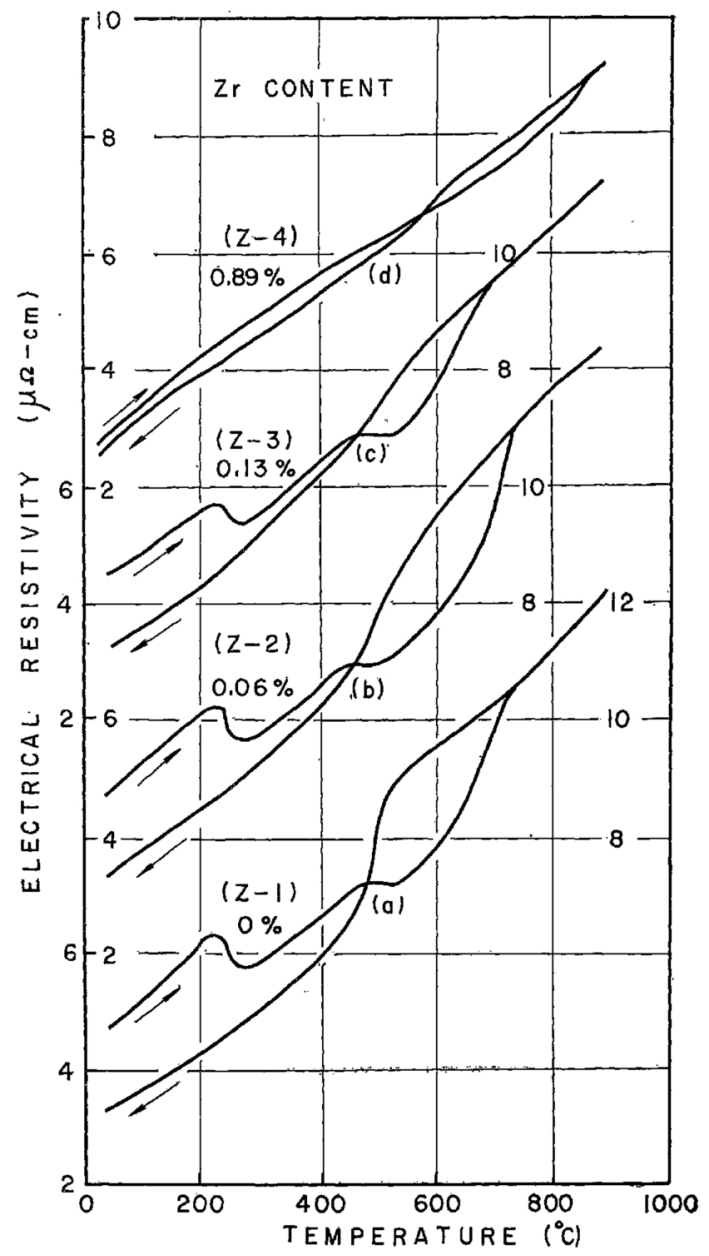

Fig. 4 Change of electrical resistivity of Cu-Ni-P alloys containing $\mathrm{Zr}$ quenched from $800^{\circ} \mathrm{C}$ during heating and cooling.

$530^{\circ} \mathrm{C}$ and a slight rise at $360^{\circ} \mathrm{C}$. In other words, it is quite clear that the precipitation occurs in two stages. The specimens with $0.06 \mathrm{wt} \% \mathrm{Zr}$ show depres. sions in their electrical resistivity values at two points of $290^{\circ} \mathrm{C}$ and $530^{\circ} \mathrm{C}$, as shown in Fig. 4 (b). In other words, the precipitation also occurs in two stages. During cooling, bends occur at two points of 750 ${ }^{\circ} \mathrm{C}$ and $530^{\circ} \mathrm{C}$. In containing $0.13 \mathrm{wt} \% \mathrm{Zr}$ depressions in the electrical resistivity occur at two points of 270 ${ }^{\circ} \mathrm{C}$ and $530^{\circ} \mathrm{C}$ as shown in Fig.4 (c). Thus it is clear that again there is a two-stage precipitation. For cooling, bends appear in the vicinity of $700^{\circ} \mathrm{C}$ and 530 ${ }^{\circ} \mathrm{C}$ though not clear. In the specimens containing 0.89 wt $\%$ of zirconium, the electrical resistivity changes in a practically linear pattern during both heating and cooling as shown in Fig. 4(d). This shows that no variations in the electrical resistivity caused by precipitation could be detected.

\section{Structural changes accompanying aging}

No precipitate appears at all when the specimens containing no $\mathrm{Zr}$ are aged at $300^{\circ} \mathrm{C}$ and $500^{\circ} \mathrm{C}$. There 
is a considerable change in the structure of the alloys containing zirconium. Photo. 1 is an electron micrograph of an alloy containing 0.06 wt $\% \mathrm{Zr}$ which was aged at $300^{\circ} \mathrm{C}$. Since there is almost no difference between this structure and the quenching structure, the

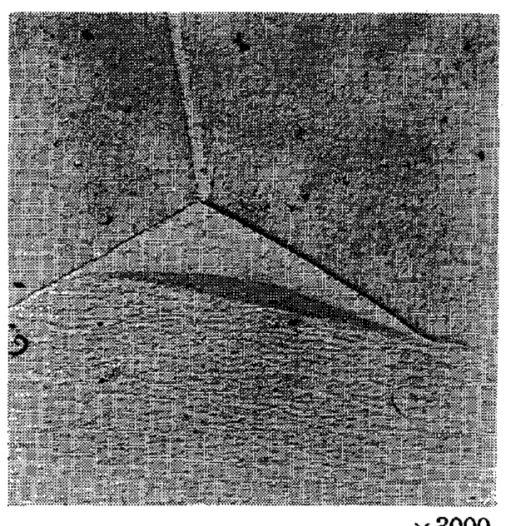

Photo 1. Aged at $300^{\circ} \mathrm{C}$ for $1 \mathrm{hr}$, $(0.06 \mathrm{wt} \% \mathrm{Zr})$

second phase present in the specimens is considered to have already existed in the quenched state. Therefore, it is probable that no new precipitate phase appears during the aging. In addition, it was found that when the amount of the zirconium content increased, the only effect was an increase in the size of the second phase and the structure after aging did not differ from that in the quenched state.

\section{Considerations}

When $0.06 \%$ zirconium is added, there is a slight increase in the softening temperature of the worked specimens. However, when 0.13 and $0.89 \mathrm{wt} \% \mathrm{Zr}$ are added, the softening temperature falls by about $40^{\circ} \mathrm{C}$ and $120^{\circ} \mathrm{C}$, respectively. Consequently, the addition of zirconium has little effect in raising the softening temperature. In fact, if excessive zirconium is added, the softening temperature will show an extreme drop. As shown clearly in the experiments on the effect of temperature on the age-hardening and the electrical resistivity when small amounts of zirconium are added, there is a very little difference in the pattern of precipitation in Cu-Ni-P alloys. When a large amount of zirconium $(0.89 \mathrm{wt} \%)$ is added, the precipitation is entirely inhibited.

When the alloys containing no zirconium are annealed at $1000^{\circ} \mathrm{C}$, the tensile strength is $22 \mathrm{~kg} / \mathrm{mm}^{2}$, whereas a tensile strength of $29 \sim 31 \mathrm{~kg} / \mathrm{mm}^{2}$ is obtained in the specimens having the zirconium content of $0.06 \sim 0.13 \mathrm{wt} \%$. In other words, this shows that the addition of a small quantity of zirconium is quite effective to prevent a drop of tensile strength at about $1000^{\circ} \mathrm{C}$. This can be understood clearly by examining the size of the grains after annealing at $1000^{\circ} \mathrm{C}$. This indicates a possibility of preventing the coarsening of grains by adding zirconium: the grain size (mean diameter) is reduced to about $1 / 50$ by the addition of 0.89 wt \% Zr.

As for the variations in electrical resistivity during heating, there is a large difference between the alloys containing $0 \sim 0.13 \mathrm{wt} \% \mathrm{Zr}$ and those containing 0.89 wt $\% \mathrm{Zr}$. In the former, there are changes in electrical resistivity due to precipitation, but such changes do not occur in the latter. It appears quite clear that precipitation does not occur in the specimens with an 0.89 $\%$ addition of zirconium, because during aging there is practically no variation in tensile strength, hardness, and electrical resistivity. Therefore, it may be concluded that these specimens are not objects of possible improvements in the properties of Cu-Ni-P alloys.

Although many workers have performed experiments on the precipitation of Cu-Ni-P alloys, it has not been discovered that the precipitation occurs in two stages. For example, the range of Crampton and Burghoff(6) merely reported the aging temperature to be from $425^{\circ} \mathrm{C}$ to $480^{\circ} \mathrm{C}$. The fact that precipitation occurs in two stages is clearly revealed by measurements of the electrical resistivity during the heating. However, the tensile strength of the aged specimens containing $0.06 \mathrm{wt} \% \mathrm{Zr}$ indicates only a vague tendency and there are no clear-cut indications of the two stages. If the precipitation peak at $300^{\circ} \mathrm{C}$ is overlapped with the precipitation peak at $500^{\circ} \mathrm{C}$, there will be a peak of the tensile strength within the range of $300^{\circ}$ $\sim 500^{\circ} \mathrm{C}$, and hence it looks as if precipitation had occurred in a single stage. At any rate, it may be a newly established fact that precipitation occurs in two stages. The fact that the addition of zirconium to $\mathrm{Cu}$ Ni-P alloys amounting up to 0.13 wt \% does not bring about any substantial change in the pattern of this two-stage precipitation has an important significance from the viewpoint of the applications of these materials.

With specimens age-hardened at $300^{\circ} \mathrm{C}$ and $500^{\circ} \mathrm{C}$ to the peak of the two-stage precipitation, both the optical microscopic structure and the elctron microscopic structure were found to differ in no way from the quenched structure, and therefore no precipitates were observed. However the existence of a second phase is reported by Crampton and Burghoff.(6) This divergence in the results may be due to differences in the experimental methods : In the experiments of Crampton and Burghoff, the specimen was cooled gradually from a high temperature at intervals of $100^{\circ} \mathrm{C}$, and water-quenched after keeping the specimen at each tempera ture for $24 \mathrm{hr}$. In the present experiment, specimens of Cu-Ni-P alloys containing 0 wt $\%, 0.13$ wt $\%$ and 0.89 wt $\% \mathrm{Zr}$ which were quenched after heating at $800^{\circ} \mathrm{C}$ for one hour and aged at $300^{\circ} \mathrm{C}$ for one hour and at $500^{\circ} \mathrm{C}$ for one hour. These specimens were immersed in an aqueous solution of $50 \% \mathrm{HNO}_{3}$. Then the precipitate (actually not a single but several phases) was taken as a residue and subjected to an X-ray diffraction examination. There was no residue in any of the alloys containing no zirconium. The sizes of the residues in $\mathrm{Cu}-\mathrm{Ni}-\mathrm{P}$ alloys with 0.13 wt $\%$ and 0.89 wt $\%$ of zirconium were about $0.2 \sim 5$ microns. The author obtained X-ray diffraction patterns of these residues, but the patterns did not correspond to any of A.S.T.M. data cards. Next, when a fluorescent $\mathrm{X}$-ray analysis was performed, it was found that nickel and zirconium were the chief components in each 
specimen of the alloys containing $0.13 \mathrm{wt} \% \mathrm{Zr}$, and that nickel, copper and zirconium were the chief components in each specimen of the alloy containing 0.89 wt $\% \mathrm{Zr}$.

From the above results, it appears that the precipitate of alloys containing $0.13 \mathrm{wt} \% \mathrm{Zr}$ contains a compound of nickel and zirconinm (presumably $\mathrm{Ni}_{3} \mathrm{Zr}$ ), and that the precipitate of alloys containing $0.89 \mathrm{wt} \% \mathrm{Zr}$ is composed of a compound of nickel and zirconium and a compound of copper and zirconiun (presumably $\mathrm{Ni}_{3} \mathrm{Zr}$ and $\mathrm{Cu}_{3} \mathrm{Zr}$ ). Although Crampton and Burghoff stated that the precipitate from the alloy is probably $\mathrm{Ni}_{5} \mathrm{P}_{2}{ }^{(6)}$, the presence of any precipitates in the alloys containing zirconium could not be ascertained since residues were not obtained in this experiment. However, the phenomenon of a two-stage precipitation occurring in alloys containing $0 \sim 0.13 \mathrm{wt} \% \mathrm{Zr}$ was considered to be due to the precipitation of separate stable precipitation phases at $300^{\circ}$ and $500^{\circ} \mathrm{C}$. It still remains unclear whether the G.P.zone or an intermediate precipitation phase is formed before the appearance of the stable precipitation phases in this alloy.

Next, let us consider the phenomenon of grain refinement by the addition of zirconium. The radii of atoms of copper and nickel were 1.28 and $1.25 \mathrm{KX}$, respectively. In addition, both of them have a face centered cubic structure. As a result, complete solid solution can be formed with them. However, the radii of atoms of phosphorous and zirconium are quite different, being 1.09 and $1.60 \mathrm{KX}$, respectively. In addition, their crystal structures differ from each other. As a result, the formation of a solid solution will be limited only to an extremely small range of the concentration Let us first consider zirconium. According to Pogodin et al., (8) the solid solubility of zirconium in copper is $0.8 \mathrm{wt} \%$ at $925^{\circ} \mathrm{C}, 0.7 \mathrm{wt} \%$ at $825^{\circ} \mathrm{C}$, and 0.28 wt $\%$ at $600^{\circ} \mathrm{C}$. According to Allibone and Sykes, ${ }^{(9)}$ the solid solubility of zirconium in nickel is $0.5 \mathrm{wt} \%$ or less. Consequently, it appears that in the specimens used in the present experiments an extremely small amount of zirconium would be solubule. Furthermore, it is likely that a greater part of it would form the second phase and this would be the main cause for the grain refinement. With respect to this restraining action on the crystal growth, it was previously believed that a second phase would act as a film that mechanically prevents contacts between crystals. In fact, Jeffries and others showed that the presence of a second phase in a certain amount would be effective to preventing the crystal growth. However, it has been generally admitted that a dispersed second phase is the main factor restraining crystal growth.

Zener treated the restraining effect of the second phase (inclusion) semi-quantitatively. If one supposes that the restraining power of the inclusion is in direct proportion to its radius of curvature $R i$ and that the driving force of the crystal growth is directly proportional to the mean curvature of the crystal boundaries $R$, then the crystal growth will be inhibited when these

(8) S. A. Pogodin, I.S. Shumova, and F.A. Kugucheva :Compt. rend. Acad. Sci. USSR, 27 (1940), 670.

(9) T. E. Allibone and C. Sykes : J. I. M., 39 (1928), 179. two forces are equal to each other. Thus, the following equation is obtained :

$$
R / R i=1 / f,
$$

where, $f$ is the volume fraction of the inclusions in the specimen.

There are two types of the crystal growth : continuous crystal growth and non-continuous crystal growth. The latter is frequently observed in tungsten containing $\mathrm{ThO}_{2}$, but in the present alloys containing zirconium, the former type of crystal growth was observed. According to Burke and Turnbull(10), the travel speed $G$ of the crystal boundaries at a constant temperature may be expressed by

$$
G=K^{\prime} \sigma V / R,
$$

where $V$ is the atomic volume, $\sigma$ the surface energy of the crystal boundaries, and $R$ the radius of curvature of the crystal boundary. $K^{\prime}$ is a velocity constant which depends on the temperature according to the following equation :

$$
K^{\prime}=K o^{\prime} \exp (-Q g / R T),
$$

where $Q g$ is the activation energy of crystal growth.

Let us first assume that the surface energy $\sigma$ is not dependent upon the grain size nor the extent of crystal growth. Then,

$$
R \propto D
$$

where $D$ is the mean diameter of the grains. And

$$
d D / d t \propto G .
$$

Under these assumptions, equation (2) will be written as

$$
d D / d t=K \sigma \quad V \mid D
$$

Integration of equation (6) with the initial conditions $D=D$ o at $t=0$, we have

$$
D^{2}-D_{0}^{2}=2 K \sigma V t
$$

where $K$ is a constant. It $D_{0}^{2}$ is negligibly small in comparison with $D^{2}$, as in the case where the crystal growth proceeds to a considerable degree, equation (7) can be witten as

$$
D \approx(2 K \sigma V t)^{1 / 2} \text {. }
$$

The relationship between the grain size of alloys annealed at $1000^{\circ} \mathrm{C}$ and their zirconium content shown in Fig. 5 (The data marked with in parts Fig .5 are the results of additional experiments), the results of which may be divided into two parts: the first part where the zirconium content is $0.05 \mathrm{wt} \%$ or less, and the second part where the zirconium content is more than 0.05 wt $\%$.

It may be concluded that the first part corresponds to the range of solid solubility in which a precipitation phase is not present and the equation (8) is applicable in this range and that the second part corresponds to the region in which a precipitaion phase is present and equstion ( 1 ) is applicable. Consequently, as cleary shown by equation (8), in the first part there are no wide variations in $K, \sigma$, and $V$ by the difference in

(10) F. E. Burke and D. Turnbull : Progress in Metal Phys., 3 (1952), 270. 
the zirconium content; thus there are no large differences in the grain size in this region. On the other hand, in the range where a precipitation phase appears with a small amount of the zirconium content, it is possible to reduce the grain size to be an extremely

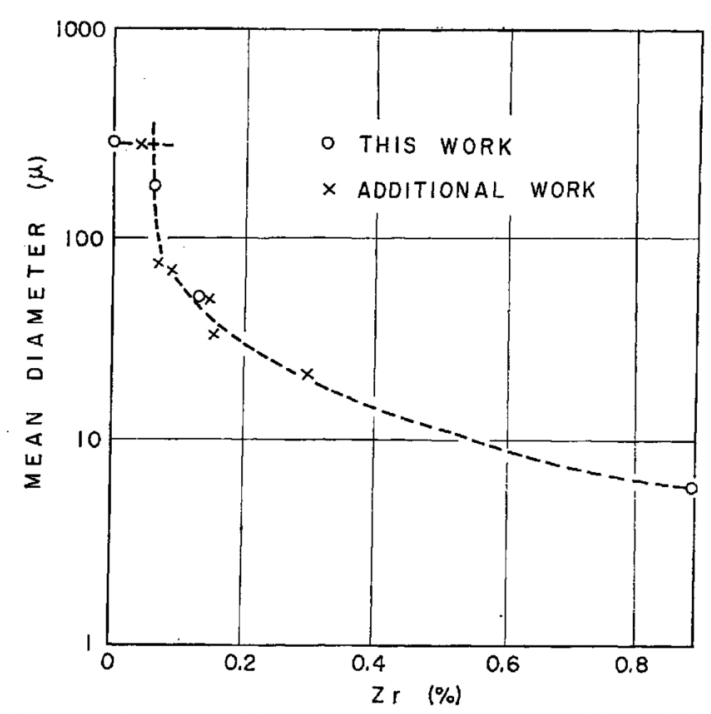

Fig. 5 Relation of $\mathrm{Zr}$ content and grain size of $\mathrm{Cu}-\mathrm{Ni}-\mathrm{P}$ alloys annealed for $1 \mathrm{hr}$ at $1000^{\circ} \mathrm{C}$. micron, respectively.

Table 3 shows both the observed values $\left(D_{\text {obs }}\right)$ and the calculated values $\left(D_{\text {cal }}\right)$ of the grain sizes specimens annealed at $1000^{\circ} \mathrm{C}$. The calculated values were obtained by the equation( 1 ) using the values mentioned above. In the calculation of $f$, it was assumed that the amount of zirconium in solid solution was $0.05 \mathrm{wt} \%$ and that the zirconium was precipitated in the form of $\mathrm{Ni}_{3} \mathrm{Zr}$ or $\mathrm{Cu}_{3} \mathrm{Zr}$. As is obvious from Table 3 , the $D_{\text {obs }}$ values are smaller than the $D_{\text {cal }}$ values, and there is a constant ratio of 0.15 between them regardless of the zirconium content. Consequently, multipling the right side of the equation (1) by the coefficient $\alpha$ (in this case, 0.15$)$, the calculated values correspond well with the observed values.

When the second phase is assumed to have a spherical shape, the diameter observed in the electron microscope on the average dislays a value equivalent to $\pi / 4$ of the maximum diameter. However, since the same is true for the $D_{\text {obs }}$ values, there is no need discussing this here. The next problem is the shape of the second phase. As seen in Photo. $2 \mathrm{~b}$, the shape considerably differs from a sphere. Therefore, this point must be taken into account. Another problem is that the

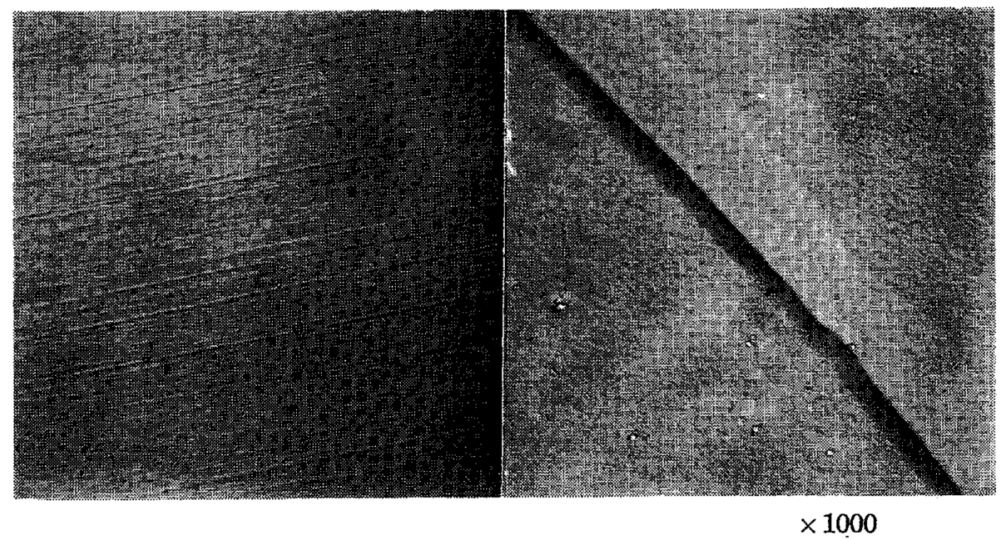

2 a $(\mathrm{Zr} 0 \mathrm{wt} \%)$

$2 \mathrm{~b}(\mathrm{Zr} 0.06 \mathrm{wt} \%)$

Photo 2. Annealed at $1000^{\circ} \mathrm{C}$ for $1 \mathrm{hr}$.

Table 3 Calculated and observed values of $D$ and $\alpha$.

\begin{tabular}{c|c|c|c|c|c|c|c|c|c|}
\hline $\mathrm{Zr}$ content $(\mathrm{wt} \%)$ & $R i(\mathrm{~mm})$ & $f$ & $R=\frac{R i}{f}(\mathrm{~mm})$ & $D_{\mathrm{cal}}(\mathrm{mm})$ & $D_{\mathrm{obs}}(\mathrm{mm})$ & $\alpha=\left(\frac{D_{\mathrm{obs}}}{D_{\mathrm{cal}}}\right)$. \\
\hline 0.06 & $1.0 \times 10^{-4}$ & $3.0 \times 10^{-4}$ & $3.33 \times 10^{-1}$ & $6.66 \times 10^{-1}$ & $1.0 \times 10^{-1}$ & $1.50 \times 10^{-1}$ \\
0.16 & $3.5 \times 10^{-4}$ & $3.3 \times 10^{-3}$ & $1.06 \times 10^{-1}$ & $2.12 \times 10^{-1}$ & $3.5 \times 10^{-2}$ & $1.65 \times 10^{-1}$ \\
0.30 & $5.0 \times 10^{-4}$ & $7.5 \times 10^{-3}$ & $6.70 \times 10^{-2}$ & $1.34 \times 10^{-1}$ & $2.0 \times 10^{-2}$ & $1.49 \times 10^{-1}$ \\
\hline
\end{tabular}

small by adding a small amount of zirconium. However, this effect is diminished in the specimens containing zirconium beyond a definite level.

In the electron microscopic structure of the specimens with $0 \mathrm{wt} \% \mathrm{Zr}$ annealed at $1000^{\circ} \mathrm{C}$, the second phase (precipitation phase) cannot be observed (Photo. 2a). In alloys containing 0.06 wt $\% \mathrm{Zr}$, the second phase is present in small quantities ; the size is approximately 0.2 microns. (Photo. 2b.)

The size of the second phase increases with the zirconium content. When the zirconium content is 0.16 wt $\%$ and $0.30 \mathrm{wt} \%$, the size is 0.7 microns and 1 grain shape is treated as spherical and the driving force of crystal growth is assumed to be directly proportional to $R$. In this respect, corrections must be made since the shape is polyhedral rather than spherical. It is believed that $\alpha$ may be considered in terms of a correcting factor for the above-mentioned second and third points.

Consequently, from the present result, the following equation may be obtained instead of equation (1) :

$$
R / R i=0.15 / f .
$$




\section{v. Conclusion}

From the above results, it is clear that copper alloys containing $1.0 \sim 1.2$ wt $\% \mathrm{Ni}, 0.20 \sim 0.24$ wt $\% \mathrm{P}$, and $0.1 \sim 0.2 \mathrm{wt} \% \mathrm{Zr}$ have a precipitation hardening which differs very little from that of alloys containing no zirconium, and the present alloys excell in that their crystals are scarcely coarsened even when heated to a high temperature. In addition, an attempt was made to clarify the mechanism of grain refinement caused by the addition of zirconium. Further research must be devoted to the process of the two-stage precipitation which was discovered during this research.

The writer expresses his gratitude to Dr. Seiji Hoshiai, director of the Central Research Laboratory, Hitachi, Ltd., who gave permission to publish this report. Thanks are also expressed to Mr. Tadashi Umezawa who was engaged in the experimental work. 